\title{
The Dual Factors and Significance of Five Liang Politics and Literature
}

$$
\text { Jiaying Liu }{ }^{1} \text {, Menghu Wang }{ }^{2}
$$

${ }^{1}$ (Department of Chinese Language and Literature of Northwest Minzu University, Lanzhou, Gansu, China, P.R.

Lanzhou City University, Lanzhou, Gansu, China, P.R.)

${ }^{2}$ (Lanzhou City University, Lanzhou, Gansu , China, P.R.)

Key words: Five liang, Politics, Literature, National cultural exchange and integration.

Abstract. Five Liang literature, is Achievements of Chinese culture and minority culture. It has unique geographical features and distinctive ethnic characteristics. It fills blank in the literary creation of this period. It adds to new factors for Sixteen State Chinese literature, and contributes to the formation of this period literature development pattern. Studying Five liang literature, is of great significance for us to further understand the political, economic, military, cultural and ethnic integration in Hexi region during the period of the Sixteen State, also has some enlightenment and reference significance to the current literature prosperity and cultural construction.

\section{五凉政教文化中的胡汉双重因素}

\author{
刘佳莹 ${ }^{1}$, 王梦湖 ${ }^{2}$, \\ ${ }^{1}$ 西北民族大学文学院，博士生，兰州，甘肃，中国 730070 \\ 兰州城市学院，讲师，兰州，甘肃，中国 730070 \\ ${ }^{2}$ 兰州城市学院，副教授，兰州，甘肃，中国 730070
}

关键词：五凉；政治；文化；胡汉；涵化

中文摘要. 公元四世纪前后是中国历史上政权更迭、民族融合的重要时期，为多民族文化的交 流提供了广阔的舞台。胡汉文化的交融, 打破了种族、血统的隔阂, 变夷从夏改建了文化体 系，为民族文化发展开拓了空间。本文希从五凉文化中的胡汉交互为切入点，将五凉政教文 化置于南北文学发展、东西贯通的视野下进行考察，旨在深入挖掘中古多民族文化交融的内 在动力，“河西文化因子”成为中华文明拓边发展，文脉伏流存休的关键。

\section{1.引论}

永熙至永嘉，中州兵祸不断，衣冠南渡后形成了南北朝政权的对立。随着中原王朝的衰 落，传统的“制边”政策无法推行继续，民族的大迁移与各少数民族先后实现对中原地区的统 治，历史为他们提供了机遇，通过种种活动将自己的民族地位和作用凸显出来。中原荒乱动 荡下，河西走廊有着较为稳定的局面。胡汉各族先后入主中国北方，胡族学习并融入中华文 明之中，汉族也在吸收借鉴更有活力的文化，促进了多民族文化的共同发展。

五凉政权之下，胡汉多元文化的此消彼长、相互碰撞交融。从地理空间上看。狭长的河 西走廊像是一条纽带, 牢牢地连接着西域和中原。“它既是汉文化的边缘文化区, 亦是西域各 少数民族文化的边缘地带，其边缘性或者说过渡性的文化特征鲜明。族际间文化互动为各民 
族文化相互借鉴、吸收提供了便利条件。"1因此, 河西地区在公元四到五世纪, 南北割据, 战 乱不休的大环境下，其安定局势使得多民族文化得以存在，并喘息发展，五胡十六国时期， 五凉文学作为民族间文化交流的典型范例, 其蕴含的胡汉双重文化因素, 在整个中国文化中 有着独特的意义。值得深入探究。

\section{2.“濡化”与“涵融”为文化发展提供保证。}

“濡化”是台湾著名学者殷海光在其著作《中国文化的展望》中提出的关于“文化变迁”的一 个概念, 主要指“濡化是文化变迁的一个程序, 在这个程序中, 两个或两个以上的文化联续着 发生接触, 结果是其中一个文化吸收了另一个文化的要素”2。公元三至五世纪, 整个北方因征 战内徙中不断消耗, 而导致整个文教事业陷入衰落时, 河西地区却峰回路转地出现了例外。 “中州板荡，戎狄交侵，僭伪相属，生灵涂炭，故文章黜焉”，但“其能潜思于战争之间，挥翰 于锋镝之下，亦有时而间出矣。…..”五凉的统治者为生存发展而增强实力，各自在一定程度 上采用了比较清明的政策, 文教事业也有蓬勃之态。

尊晋攘外，保宁域内，学尚明察，敬贤爱士。如张轨、李暠所建立的前凉和西凉，张轨 “令有司可推详立州已来清贞德素、嘉遁遗荣、高才硕学、著述经史......具状以闻, 州中父老 莫不相庆。”3本土的学者和中原流亡到此的名流汇聚于河西地区, 成就了五凉文教昌明的气 象。为汉晋文化存续之关键。北魏时期有云“凉州虽地处戎域，然自张氏以来，号有华风。”4 “世笃忠厚”的风气吸引了民众落户安居。西凉李暠自述言道“窃以诸事草创, 仓帑未盈, 故息 兵案甲, 务农养士。”在统辖内颇现文治之风, 并告诫诸子在治理中做到详审真伪, 远传近忠, 刑狱宽简, 勤勉案讼等等, “慎勿以情轻加声色。赏勿漏疏, 罚勿容亲。禁御左右, 勿作威福。 勿伐善施劳, 逆诈亿必, 以示己明。广加谘义, 无自专用......”安定社会、抚恤民众的主张在 当时殊为难能。

奉朔正统，延揽人才，内修政事，外礼英贤。胡族酋豪在扩充地盘先后都奉朔通表，使 得 “奉中兴年号, 百姓悦之”。在当时普通百姓心目中，东晋南朝才是华夏正统。这种观念由 华夏民族波及周边的各少数民族,有一定感召力和激励性。那些“河西斗绝”的胡族政权，参与 北方社会生活的意识正在提高, 他们也懂得用兴理文教实为稳定统治, 大多都奉晋朝为正统, 获得政治声誉。这不失为割据纷争中的权宜之计。吕光初定河西时，也曾经因忌惮杜进而诛 杀之。后受段业棟言下令责躬, 一定程度上推崇宽简之政。南凉秃发乌孤的一个小朝廷，网 罗汇集了各民族地区的头面人物, 其中不乏河西著姓或是中原冠冕。靠着他们的辅助襄赞, 南凉的政治武功逐步展开。北凉沮渠氏将广开贤路和搜求良言作为立国资政的措施，受到士 族儒生的拥护。蒙逊曾委任被俘的西郡太守杨统为右长史, 其容忍人雅量, 气度非常。即使 降将如敦煌张穆, 亦因其“博通经史, 才藻清瞻, 擢拜中书侍郎, 委以机密之任”。能做到唯才 是举，知人善用。北凉前期才能申修吏治，具百废待兴之象。

\section{3.文学作家身份胡汉皆有且多为割据豪酋和世家官吏}

在统治阶层的积极倡导、身体力行下，五凉文学创作从战乱中的惨淡寂胗走向复兴。无 论是自觉学习效仿汉晋文化的统治者, 还是博学通达以经学、文艺著称的汉族大儒们, 从这 一时期的文学作品里我们可以窥见, 整体风貌与南方重清丽抒情不同, 北方文风尚刚健实用。 十六国时期陇右汉族作家的胡化过程，既与“五凉”政权的统治政策有关，又受到河西地区日

\footnotetext{
1 霍志军; “论十六国时期张骏、李高、秃发废檀、沮渠蒙逊、吕光的文学活动” 《天水师范学院学报》

殷海光著《中国文化的展望》上海三联书店 2002 年 P46。

${ }^{3}$ 《晋书》卷 86 《张轨传》。

${ }^{4}$ 《魏书》卷 52 《胡舅传》

5 《晋书》卷 87 《凉武昭王李玄盛传》

${ }^{6}$ 《晋书》卷 87 《凉武昭王李玄盛传》
} 
益多元的文化倾向之影响。这一时期纯粹的文学家甚少，主要是以君主和官员士族为主的创 作者。五凉文学中发展最充分的两个政权是西凉与北凉。西凉李暠本身有着家学传统, 擅长 著文作赋，而北凉沮渠氏为少数民族代表，也能得以传承文教，与沮渠蒙逊本人 “博涉群史， 颇晓天文, 雄杰有英略, 滑稽善权变”有很大关系。五凉时期因崔浩之祸, 大量书籍被销毁, 可见当时创作实际还当远不止此。十六国文学的一度繁荣, 在于割据君主与臣僚的通力合作, 积极倡导、主动接受先进的汉文化有着密切的关联。

五凉文学发展有以下几个原因：一、大环境下，中原与西域文明的硕果交汇于此，两种 文化的交回地带充满了生机。二、统治者具备一定文化水平, 多雅好文学, 实际出发去倡导, 并将文化实用与政治教化交织在一起。五凉时期的现存作品绝大多数为应用文字，诸如书、 表、奏议、铭颂等等，各胡族之主之尚文无疑是一种政治行为，“代表着一种国家意志，可以 说是他们建业立国和巩固统治的必要条件。”柳诒徵在《中国文化史》云: “自晋以降之史策, 殆血史耳。然自文化一方观之，则诸族布在中夏，亦多同化于中国之文教。”的 三、当权者与 地方豪族势力的相互依存, 重用通晓儒学文化的汉族士人, 也是为了得到这些学者认同, 合 作是要基于文化传统的共识。

河陇政权更替频繁，而文化却得以持续繁荣。所以才有了“凉州虽残弊之后，风化未颓。” 以李暠为例, 李暠本人学术与河西冠带有承继关联。其人善赋诗作序, 通涉经史。“玄盛立靖 恭堂亲为序颂，以明鉴戒之义; 当时文武群僚亦皆图焉”。“玄盛上巳日宴于曲水，命群僚赋 诗, 而亲为之序..... 又著《槐树赋》以寄情, 盖叹僻陃遐方, 立功非所也。亦命主簿梁中庸 及刘彦明等并作文, 感兵难繁兴, 时俗宣竟, 乃著《大酒容赋》以表恬豁之怀......自余诗赋 数十篇”。 ${ }^{2}$ 上有所好，下必从之。龙飞二年（397 年）冯翊等人劝李高自领太守时说道“白额 驹今已生矣。”劝诫的话如此通俗浅进似口头语, 仿佛是游牧民族脱口而出的家常语。在多民 族文化影响下, 汉族作家创作使用了典型的胡化意象, 带上了一抹异域风情。主要表现为人 际交往的本土化, 对胡人生活方式的融合接纳和人格气质以及情感心态之变化。生机勃勃的 北方游牧文化为中华文化带来了活力。”3

\section{4.文学创作上呈现拓边与伏流的效果。}

以创作群体和诗文总量来看, 十六国时期, 五凉文学在北中国并非是最鼎盛的、最丰硕 的, 作品数量无法与前秦相较。加上大量作品的残缺、佚失使得研究材料比较溃乏。现存的 材料也多为军国文翰。其文化意义更多是对少数民族文学表现主题和形式的开拓, 文学脉络 发展的伏流不绝。4

这一时期的文学作品，以编修史籍、实用文章、撰写词赋最为称道。因修史而得以重用 者如索绥因编修完成《凉春秋》而受到继任的张重华重用, 封为平乐亭侯。隐居于临松的儒 学大师郭荷著有《春秋墨说》、《孝经错纬》等典籍。后学刘昞学识渊博, 注释书籍不倦, 且 谦逊勤勉, 李暠给予极高评价“注记篇籍, 以烛继昼”。其注后世史家评为“断珪残璧, 少而益 珍”，惜存世者胗骞。在政权割据、动荡时代，官修史书的可能性减弱，而私人著述不仅起到 了纪录历史、保存文献，也是秉承汉晋一统以来的政道。士人处于安稳局面后，从事兴办私 学、修订文史、咏和酬唱等文化活动; 因其突破陈规, 使被潜抑的美学因素找到新的艺术形 式，是北方游牧文明对中原文明造成结构性震荡所留下的一项时代性成果。”5他们是推动五 凉时期文化和学术发展的中坚，在野与在朝的士人皆是推动河西文明发展的骨干力量。

五凉的抒情的文学作品不甚发达，作品也多是实用性文章，诸如书、表、疏等。前凉张

\footnotetext{
1 柳诒徵《中国文化史》中册 长沙: 湖南大学出版社 2014, P543。

2 《晋书》卷 87 《凉武昭王李玄盛传》

3 霍志军; “论十六国时期张骏、李畗、秃发废檀、沮渠蒙逊、吕光的文学活动” 《天水师范学院学报》

4 蔡丹君 “乡里社会与十六国北朝文学的本土复兴” 《文学遗产》2 017 年第 1 期

5 杨义.国古典文学图志一一宋、辽、西夏、金、回鹘、吐蕃、大理国、元代卷 $[\mathrm{M}]$.北京:生活・读书・新知三联书店 2006 年
} 
骏的《上疏请讨石虎李期》、张重华的《上疏请伐秦》、宋纤的《上疏辞张祚》、张天赐的 《答索商》、《遗郭瑀书》、张琠的《表留张轨》等, 刘劦思在《文心雕龙·章表》里标举张骏 其文，并赞誉它“文致耿介”，为“陈事之美表。”这些文翰皆辞藻华美，骈俪俱佳，质朴刚健的 北地文风中流露出清丽的味道。十六国时期的词赋虽大多缺失或散佚, 具名可查的大致仅有 十来篇。留存完整的作品仅剩西凉李暠长达千字的《述志赋》。五凉文学与汉晋文学之间的 承绍关系，可以说十六国散文特有的骈俪化气息为此前文学传统的一个延续。

\section{5.结论}

综上所述，河陇地区民族众多，自西汉移民实边之后，汉族与游牧民族交错杂居。几个 世纪的发展，五凉政权利用它们在河西走廊建制的政治优势，担负起承前启后的历史使命。1 在政治上，整顿吏治，、革新制度、任用贤才。文教上，推崇儒学，兴办学校，重视文化交 流。尤其是文学这块, 这一时期胡汉双重文化因子发挥极大效力, 为了中古文化发展注入新 的力量, 增添了新的格局。

\section{致谢}

本文为兰州城市学院青年教师项目《南北视域相互关照下的五凉文化与中原文化的交流》 的成果。项目编号: LZCU-QN2017-16

\section{References}

[1] Fang Xuanling, Book of the Jin Dynasties, ZhongHua Book Company, 1974.

[2] Li YanShou, the History of the Northern Dynasties, ZhongHua Book Company, 1974.

[3] Wei Shou, The History of Wei Dynasty ,ZhongHua Book Company ,1974.

[4] Tang Qiu, Sixteen Country of The Spring and Autumn ,ZhongHua Book Company, 1985.

[5] Yan Kejun, The Whole Ancient Times, Three Generations, Qin and Han dynasty, The Three Kingdoms and Sixdynasty's Articles ,ZhongHua Book Company, 1958.

[6] Chen Yinque, Preliminary to the Origin of Institutions of the Sui and the Tang, Shanghai Ancient Books Publishing House, 1982.

[7] Cao Daoheng, A Survey Of The Sixteen Writers, A Collection Of Essays On The History Of Medieval Literature, ZhongHua Book Company, 1986.

[8] Zhao Yiwu, On the evaluation of wuliang literature ,Gansu social science, no. 4,1989.

[9] Cao Daoheng, Shen Yucheng, Literary history of the northern and southern dynasties, People's Literature Publishing House, 1991.

[10] Zhao Xiangqun, The History of five Liang, Gansu people's publishing house, 1996.

[11] Zhou Jianjiang, The Northern Dynasties History of Literature ,China Social Sciences Press, 1997.

[12] Hu Axiang, Wei-Jin period Hexi Region History of Literature, Journal of Luoyang University, 2002 .

[13] Chen Yinque, Wan Shengnan, History of the Wei, Jin and the Southern and Northern Dynasties

\footnotetext{
1 赵向群.《五凉史探》甘肃人民出版社, 1996.
} 
Lectures, Guizhou people's publishing house, 2007.

[14] Gao Renxiong, The Northern Dynasties History of Literature of National Minorities, ZhongHua Book Company, 2011. 